\title{
Concurrent genetic alterations in DNA polymerase proofreading and mismatch repair in human colorectal cancer
}

\begin{abstract}
Rintaro Yoshida ${ }^{1}$, Kaname Miyashita ${ }^{2}$, Mayuko Inoue $^{3}$, Akiyoshi Shimamoto ${ }^{3}$, Zhao Yan ${ }^{4}$, Akinori Egashira ${ }^{1}$, Eiji $\mathrm{Oki}^{1}$, Yoshishiro Kakeji ${ }^{1}$, Shinya Oda ${ }^{\star, 3}$ and Yoshihiko Maehara ${ }^{1}$

Genomic sequences encoding the $3^{\prime}$ exonuclease (proofreading) domains of both replicative DNA polymerases, pol delta and pol epsilon, were explored simultaneously in human colorectal carcinomas including six established cell lines. Three unequivocal sequence alterations, including one previously reported, were found, and all these were considered as dysfunctional mutations in light of the local amino-acid sequences. In particular, the F367S mutation found in the POLE gene encoding the pol epsilon catalytic subunit, which includes the proofreading domain, is the first found in human diseases. Surprisingly, the tumours carrying these proofreading domain mutations were all defective in DNA mismatch repair (MMR). In addition to the two cell lines with acknowledged MMR gene mutations, the third tumour was also demonstrated to harbour a distinct mutation in MLH1, and indeed exhibited a microsatellite-unstable phenotype. These findings suggest that, in concert with MMR deficiency, defective polymerase proofreading may also contribute to the mutator phenotype observed in human colorectal cancer. Our observations may suggest previously unrecognised complexities in the molecular abnormalities underlying the mutator phenotype in human neoplasms.
\end{abstract} European Journal of Human Genetics (2011) 19, 320-325; doi:10.1038/ejhg.2010.216; published online 15 December 2010

Keywords: polymerase delta; polymerase epsilon; proofreading domain; colorectal cancer

\section{INTRODUCTION}

Mutation rates on the genome are invariably regulated and typically suppressed to an extremely low level, such as $10^{-10}$ per base replicated, in the organisms. ${ }^{1}$ The high fidelity of DNA replication is achieved by several molecular mechanisms. The frequency of erroneous nucleotide incorporation is indeed extremely low compared with that expected from base-pairing energetics, and the vast reduction of the misincorporation frequency involves three steps of molecular events: (a) correct incorporation of complementary nucleotides by DNA polymerases, (b) removal of the newly added nucleotides, particularly incorrectly paired nucleotides, by the $3^{\prime}$ exonuclease activities associated with the DNA polymerases (proofreading) and (c) postreplicative scanning of mispaired bases by DNA mismatch repair (MMR). ${ }^{2,3}$ Various Escherichia coli (E. coli) mutator strains have been used to study these molecular mechanisms by which organisms maintain their mutation rates at very low levels. The dna $Q^{+}\left(m u t D^{+}\right)$gene of $E$. coli encodes the epsilon subunit of the DNA polymerase III holoenzyme that is involved in $3^{\prime}$ exonuclease proofreading activity, ${ }^{4}$ and, therefore, the mutation frequencies in the $d n a Q$ mutators are sometimes 1000-10 000 times higher than the wild-type levels. ${ }^{4,5}$ In E. coli, MMR is chiefly directed by the proteins encoded by the three genes: $m u t S^{+}$, $m u t L^{+}$and $m u t H^{+}{ }^{6}$ The $m u t S$ or $m u t L$ mutators exhibit an approximately 100 times increase in the mutation frequency. ${ }^{7}$ Thus, polymerase proofreading and MMR are the two major systems that counteract the replication errors caused by the DNA polymerases and, consequently, guarantee the high fidelity of DNA replication on the genome.

In 1993, mutations in the human homologues of the E. coli MMR genes were reported in the familial cancer-prone syndrome, hereditary non-polyposis colorectal cancer (HNPCC) ${ }^{8,9}$ The cellular state with an elevated mutation rate, that is, the 'mutator phenotype, ${ }^{10}$ has since then received attention as a cause for tumourigenesis. Indeed, tumours frequently arise in MMR gene-knockout mice ${ }^{11,12}$ and the mutation rates in the MMR-defective mouse cells are known to be markedly increased. ${ }^{11,13}$ Human cell lines with an acknowledged defect in the MMR genes also exhibit significantly elevated mutation rates. ${ }^{14-17}$ On the other hand, defects in polymerase proofreading have not been documented in human populations. Various types of DNA polymerases have been identified in diverse species to date. Studies on the in vitro replication of SV40 DNA have elucidated that pol alpha and delta have essential roles in chromosomal DNA replication in higher eukaryotic cells. ${ }^{18}$ Pol alpha functions at the replication folks and initiates DNA replication in the both leading- and lagging strands, synthesising the RNA primers and short stretches of DNA. Pol delta and epsilon elongate the DNA. As pol epsilon possesses a relatively high processivity, it is now widely accepted that in eukaryotic cells pol delta and epsilon are responsible for the lagging- and leading-strand synthesis, respectively, ${ }^{19}$ although pol epsilon has been demonstrated not to be essential in yeast. ${ }^{20}$ The catalytic subunits of pol delta and epsilon,

${ }^{1}$ Department of Surgery and Science, Graduate School of Medical Sciences, Kyushu University, Fukuoka, Japan; ${ }^{2}$ Department of Hematology, National Kyushu Cancer Center, Fukuoka, Japan; ${ }^{3}$ Cancer Genetics Laboratory, Institute for Clinical Research, National Kyushu Cancer Center, Fukuoka, Japan; ${ }^{4}$ The Third Surgery Department, Liaoning Cancer Hospital and Institute, Shenyang, The People's Republic of China

${ }^{*}$ Correspondence: Dr S Oda, Cancer Genetics Laboratory, Institute for Clinical Research, National Kyushu Cancer Center, 3-1-1, Notame, Minami-Ku, Fukuoka 811-1395, Japan. Tel: +81 925413231; Fax: +81 925428534; E-mail: soda@nk-cc.go.jp

Received 22 July 2010; revised 26 October 2010; accepted 27 October 2010; published online 15 December 2010 
for example, p125 $21-23$ and p261 24,25 in mammals, include the $3^{\prime}$ exonuclease, that is, proofreading, domains. Indeed, in the yeast mutants in which pol delta or epsilon proofreading is selectively inactivated, the mutations rates are 10-100 times higher than the wild-type strains. ${ }^{26-28}$ Recently, mice carrying artificial alleles with substitutions at essential amino-acid residues in the proofreading domains of pol delta ${ }^{29,30}$ and epsilon $^{31}$ have been reported. The observed mutation rates were indeed significantly elevated over the wild-type levels. ${ }^{31}$ Intriguingly, tumours arose in various organs of the animals. ${ }^{31}$ Defective polymerase proofreading warrants particular attention in human cells. However, the genomic sequences that encode proofreading domains of the both replicative DNA polymerases, pol delta and epsilon, have not previously been explored simultaneously in human diseases, particularly in human neoplasms, although the POLD1 gene encoding the p125 subunit of pol delta has been sequenced in several human colorectal tumours. ${ }^{32}$ In this present study, we first sequenced both the genomic sequences encoding the pol delta and epsilon proofreading domains in a large panel of human colorectal carcinomas, including six established human colorectal cancer cell lines, and found novel mutations in both the genes. In particular, the mutation in the POLE gene that encodes p261 catalytic subunit of pol epsilon is the first found in human cells. Furthermore, we found common and unique molecular characteristics in the proofreading-mutant tumours. Our findings may suggest previously unrecognised complexities in the molecular abnormalities underlying the mutator phenotype in human tumours.

\section{MATERIALS AND METHODS}

\section{Patients and tissue specimens}

Cancer tissues and the corresponding normal tissues were collected from 76 consecutive patients who underwent surgery in the Department of Surgery and Science, Kyushu University Hospital from 1994 to 1999. Ethical approval for this study was obtained from the IRB of Kyushu University. Specimens were taken immediately after resection and placed in liquid nitrogen. High-molecular weight chromosomal DNA was extracted and subjected to the analyses.

a POLD1

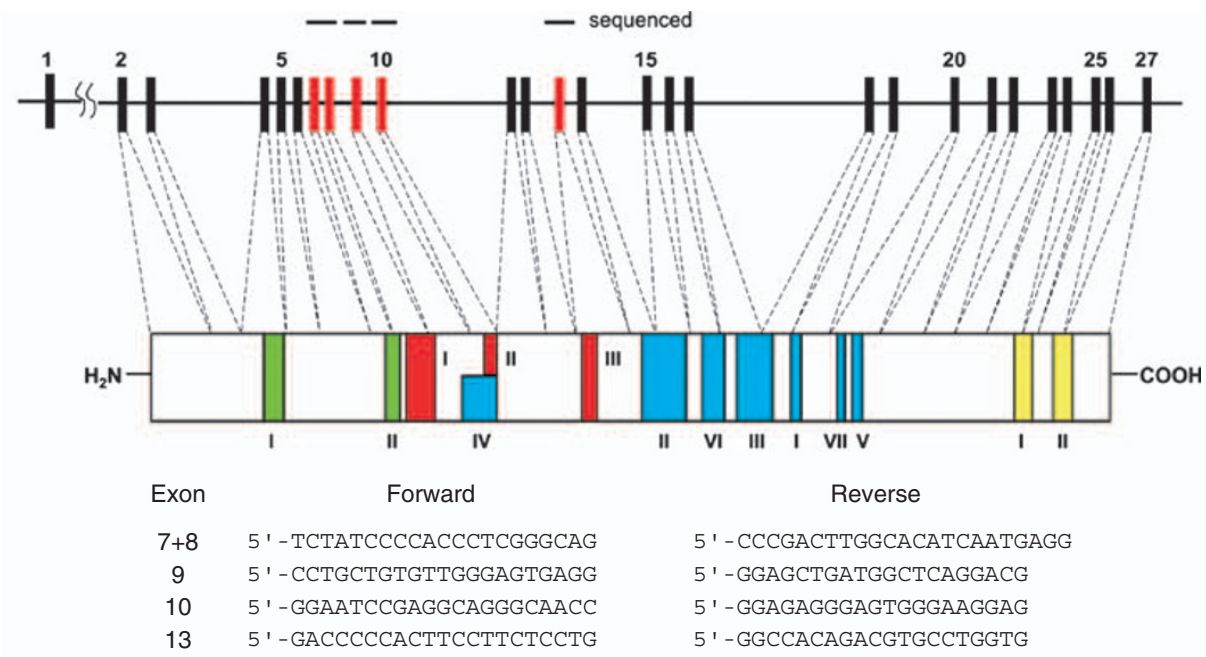

b

POLE

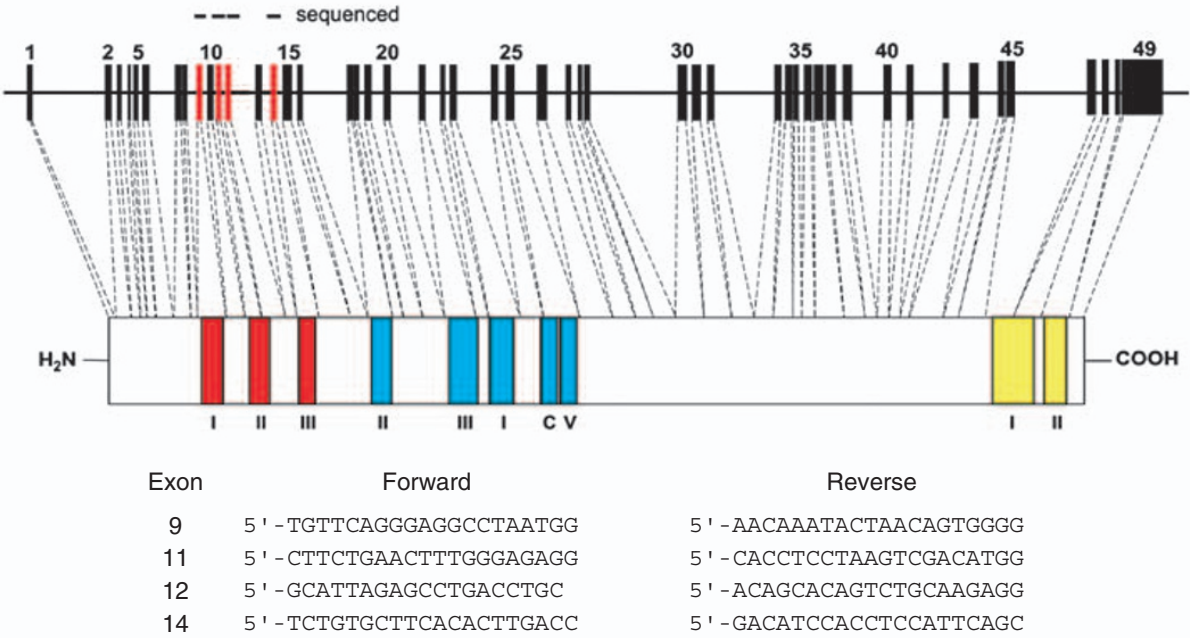

Exonuclease domain

Polymerase domain

PCNA interacting domain

Zinc finger domain

Figure 1 The genomic structures of the POLDI (a) and POLE (b) genes and the functional domains in their protein products. The exons corresponding to the $3^{\prime}$ exonuclease, that is, proofreading, domains are indicated in red and the genomic regions sequenced in this study by bar. The oligonucleotide primers used are also shown. 


\section{Cell culture}

Human colorectal adenocarcinoma cell lines, HCT116, SW620, SW48 and HT29, were distributed by the American Type Cell Culture (Rockville, MD, USA). LoVo and DLD-1 were obtained from the Japanese Cancer Research Bank (Tokyo, Japan). HCT116 and HT29 were maintained in MacCoy's 5a medium. For SW620 and SW48, L15 medium was used. DLD-1 and LoVo cells were maintained in RPMI 1640 and F12, respectively. All the media were purchased from Life Technologies, Inc. (Rockville, MD, USA) and supplemented with $10 \%$ foetal calf serum.

\section{DNA sequencing}

The 2.5-kbp genomic sequences in the POLD1 and POLE genes that encompass the regions encoding the proofreading domains of pol delta and epsilon (Figure 1) were amplified by PCR using Taq polymerase with the 3 ' exonuclease

Table 1 Clinicopathological features of 76 colorectal cancer patients

\begin{tabular}{|c|c|}
\hline Variables & Number \\
\hline \multicolumn{2}{|l|}{ Sex } \\
\hline Male & 42 \\
\hline Female & 34 \\
\hline Age (years) & 62.4 \\
\hline \multicolumn{2}{|l|}{ Location } \\
\hline Ascending colon & 23 \\
\hline Transverse colon & 6 \\
\hline Descending colon & 7 \\
\hline Sigmoid colon & 18 \\
\hline Rectum & 22 \\
\hline \multicolumn{2}{|l|}{ Stage } \\
\hline $0 / 1$ & 11 \\
\hline II & 22 \\
\hline$\|I \mid a /\| l b$ & 30 \\
\hline IV & 13 \\
\hline \multicolumn{2}{|l|}{ Histology } \\
\hline Well differentiated adenocarcinoma & 44 \\
\hline Moderately differentiated adenocarcinoma & 22 \\
\hline Poorly differentiated adenocarcinoma & 7 \\
\hline Other & 3 \\
\hline \multicolumn{2}{|l|}{ Depth } \\
\hline Mucosa & 1 \\
\hline Submucosa & 3 \\
\hline Musculuris propia & 13 \\
\hline Subserosa & 31 \\
\hline Serosa & 20 \\
\hline Invasion to surrounding tissues & 8 \\
\hline \multicolumn{2}{|l|}{ Lymph node metastasis } \\
\hline Positive & 38 \\
\hline Negative & 38 \\
\hline \multicolumn{2}{|l|}{ Lymphatic invasion } \\
\hline Positive & 28 \\
\hline Negative & 48 \\
\hline \multicolumn{2}{|l|}{ Venous invasion } \\
\hline Positive & 20 \\
\hline Negative & 56 \\
\hline
\end{tabular}

activity, EX Taq (TaKaRa Bio Inc., Otsu, Japan), and the oligonucleotide primers shown in Figure 1. PCR products were directly used as a template for cycle sequencing reactions using BigDye terminator cycle sequencing kit (Applied Biosystems, Foster City, CA, USA), and the reaction products were loaded onto ABI PRISM 310 Genetic Analyzer (Applied Biosystems). Mutations found in one PCR product were verified by reverse sequencing and finally confirmed in three independently amplified PCR products. Primer sequences for sequencing analyses of the $M L H 1$ gene were the same as reported by Kolodner et al, ${ }^{33}$ except that the additional sequence complementary for M13 universal primer was deleted. The KRAS sequence was analysed as described in our previous report. ${ }^{34}$ Sequencing analyses of TP53 (exons 5-9) were performed using $p 53$ primers (Nippon Gene, Tokyo, Japan). Mutations found were similarly confirmed in three independently amplified PCR products.

\section{Microsatellite instability}

Microsatellite analysis using fluorescence-labelled primers and an automated DNA sequencer has been described in detail. ${ }^{35}$ Five human dinucleotide microsatellites, D2S123, D5S107, D10S197, D11S904 and D13S175, were used as markers. PCR products of the microsatellite sequences were analysed using ABI PRISM 310 Genetic Analyzer (Applied Biosystems). Data were processed by ABI software, GeneScan ver. 3.1.2. (Applied Biosystems).

\section{RESULTS}

Mutations found in the genomic sequences encoding the proofreading domains of pol delta and epsilon in human colorectal cancer

High-molecular weight genomic DNA was extracted from 6 established human colorectal cancer cell lines and clinically obtained carcinoma tissue specimens derived from a panel of 76 colorectal cancer patients that is representative of the average patient population with this malignancy (Table 1). Five and four exons of human POLD1 and $P O L E$ genes, respectively, that encompass the genomic regions encoding the $3^{\prime}$ exonuclease, that is, proofreading, domains of pol delta and epsilon were amplified by PCR and sequenced by direct cycle sequencing (Figure 1a and b). Sequence alterations causing amino-acid substitutions were identified in two cell lines and one tissue sample (Figure 2, Table 2), ${ }^{36-43}$ and these sequence alterations were confirmed in three independently amplified PCR products by more than three cycle sequencing reactions. Other types of sequence alterations such as insertions/deletions were not found. Among these sequence alterations, POLD1 R506H in DLD-1 cells has been previously reported ${ }^{32,44}$ and therefore is not novel. On the other hand, POLD1 V312M in LoVo cells has not thus far been reported in the literature. In particular, POLE F367S in the IC678 tumour is the first identified sequence alteration of the POLE gene in human diseases.
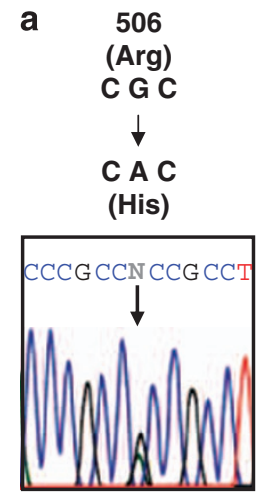

Figure 2 POLD1 and POLE mutations in human colorectal tumours. Sequence alterations found at codon 506 (DLD-1) (a) and 312 (LoVo) (b) of the POLD1 gene and codon 367 (IC678) (c) of the POLE gene are shown. Arrows indicate base changes. 
Table 2 Mutations found in proofreading-mutant colorectal carcinomas

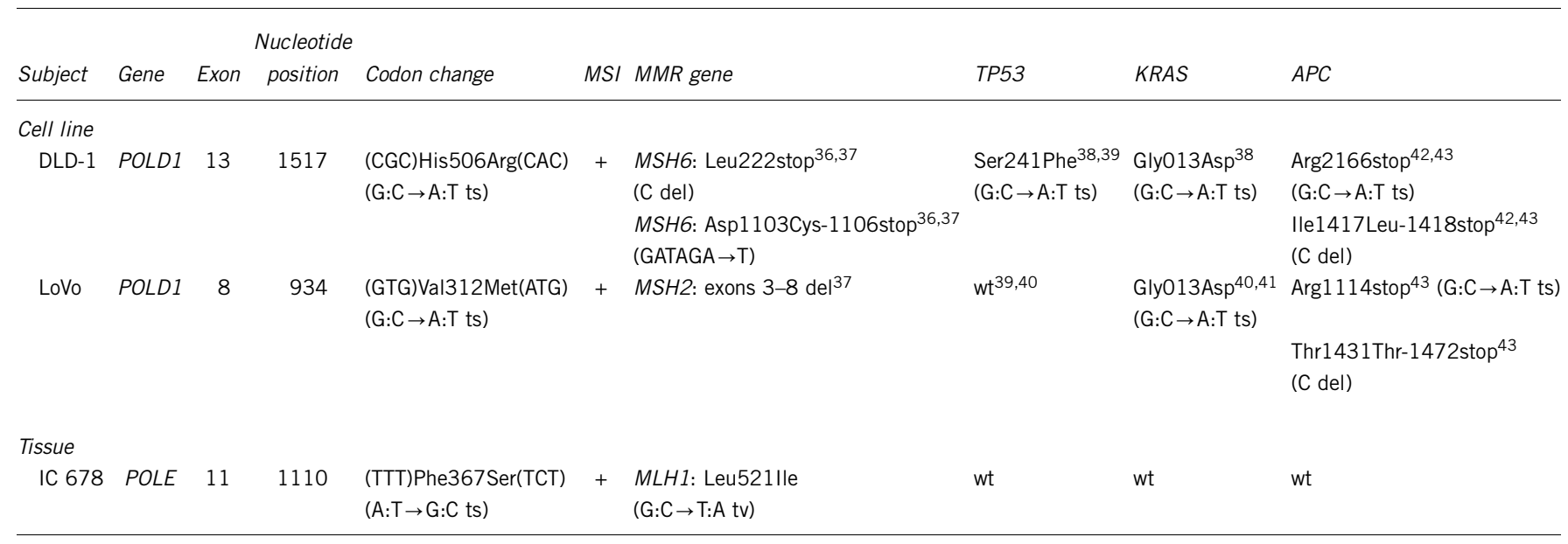

Abbreviations: del, deletion; MSI, microsatellite instability; ts, transition; tv, transversion; wt, wild type.

POLD1 has previously been explored in a limited number of human colorectal carcinoma tissue specimens, and no sequence alterations causing amino-acid substitutions were found in the genomic sequences encoding the proofreading domain. ${ }^{32}$ Similarly, we identified no POLD1 alterations in a relatively large panel of colorectal cancer patients.

To discuss the significance of these sequence alterations, we compared the local amino-acid sequences among several different organisms (Figure 3). Arginine residues at codon 506 of the POLD1 gene are highly conserved from yeast to mammals ${ }^{21,44}$ and, therefore, $\mathrm{R} 506 \mathrm{H}$ in DLD-1 cells is regarded as impairing the protein function and, consequently, as a dysfunctional mutation. ${ }^{44}$ Valine residues at codon 312 are also conserved between mouse and human, although differing in yeast. ${ }^{21,45,46}$ Intriguingly, phenylalanine residues of the first identified sequence alteration in POLE, F367S, is highly conserved in these four organisms, ${ }^{47}$ suggesting that $\mathrm{F} 367 \mathrm{~S}$ is dysfunctional and possibly pathogenic. We thus found two novel and one known mutations in the genomic sequences encoding the proofreading domains of pol delta and epsilon in two human colorectal cancer cell lines and one colorectal carcinoma tissue. These mutations have not been confirmed using genomic DNA extracted from the corresponding normal tissues. The IC678 tumour carrying the POLE mutation was derived from a male rectal cancer patient without any remarkable clinicopathological features.

MMR deficiency in proofreading-mutant colorectal carcinomas One important common characteristic of DLD-1 and LoVo cells is that both cell lines are defective in MMR. A large deletion involving from exons 3-8 of one of the essential human MMR genes, $M S H 2$, has been reported in LoVo cells (Table 2) and, therefore, LoVo cells have been regarded as MMR-deficient. Indeed, LoVo cells exhibit a remarkable phenotype with microsatellite instability (MSI), ${ }^{40}$ a hallmark genomic change observed in MMR-defective cells. On the other hand, DLD-1 cells are known to harbour a 1-bp deletion mutation at codon 222 of one allele of another important MMR gene, MSH6, and a sequence deletion/insertion involving 5-bp in the other allele (Table 2). As a consequence, MSH6 protein is not expressed in DLD-1 cells. $^{36,48}$ Intriguingly, the IC678 tumour also exhibits a MMRdefective phenotype ${ }^{49}$ As shown in Figure $4 \mathrm{a}$, alterations in a human dinucleotide microsatellite, D13S175, were readily detected

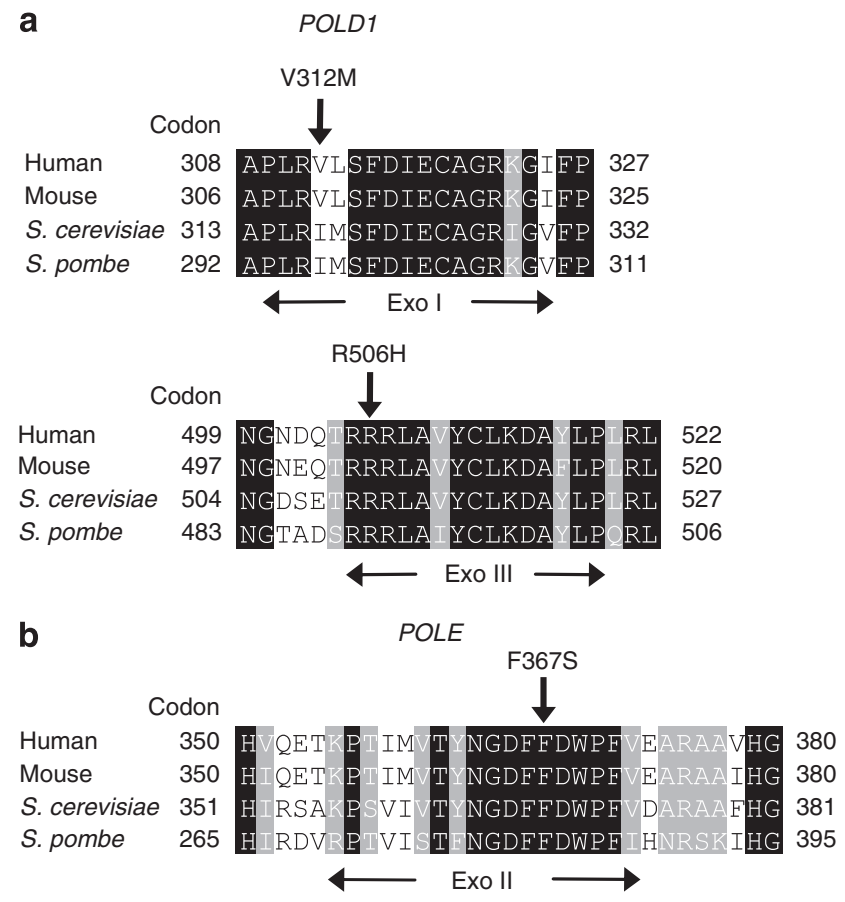

Figure 3 Comparison of the local amino-acid sequences encoded by POLD1 (a) and POLE (b) among the different species. Amino-acid substitutions found in human colorectal tumours are indicated by vertical arrows.

in the genomic DNA extracted from this tumour. Indeed, a sequence alteration resulting in an amino-acid substitution was found at codon 521 of another essential MMR gene, MLH1 (Figure 4b). ${ }^{49}$ As normal leucine residues in this codon are conserved from yeast to human, ${ }^{50}$ this sequence alteration, L521I, may be regarded as a dysfunctional mutation. Thus, all the three subjects that carry POLD1 or POLE proofreading domain mutations indicate MMR deficiency.

We further sequenced the APC, KRAS, TP53 genes, the alterations of which are known to play crucial roles in colorectal tumourigenesis, ${ }^{51-53}$ in the IC678 tumour. However, we found no detectable 
a

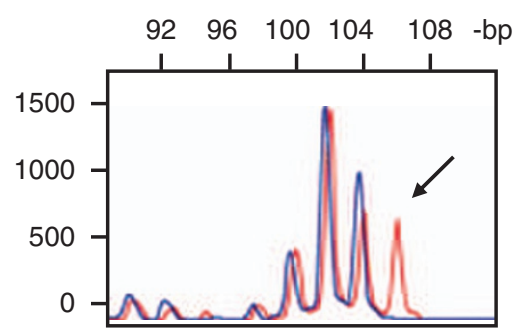

Figure 4 The proofreading-mutant human colorectal tumour, IC678, exhibits a microsatellite-unstable phenotype and harbours a mutation in a DNA MMR gene. (a) In the genomic DNA samples prepared from the tumour and the corresponding normal tissues, the human microsatellite sequences were amplified by PCR using differentially fluorescence-labelled primers and electrophoresed simultaneously in an automated sequencer. Results obtained in D13S175 are shown: red lines, cancer; and blue lines, normal mucosa. Fragment length alteration indicating microsatellite instability is evident (pointed by arrow). (b) Sequencing analyses revealed a base substitution in $M L H 1$.

sequence alterations in these genes (Table 2), whereas several mutations have been reported in DLD-1 and LoVo cells and, in particular, DLD-1 cells harbour mutations in all these three genes (Table 2).

\section{DISCUSSION}

The genomic sequence of $P O L D 1$ has previously been examined in six human colorectal cancer cell lines and seven clinically obtained colorectal carcinoma tissues, and several sequence alterations, including possible polymorphisms, were reported. ${ }^{32}$ However, apart from the previously reported R506H mutation in DLD-1 cells, no sequence alterations resulting in amino-acid substitutions were found in the genomic regions encoding the proofreading domain. In this present study, using a relatively large panel of colorectal carcinomas, we first elucidated that $P O L D 1$ proofreading domain mutations were indeed infrequent in colorectal cancer patients. Nevertheless, in addition to the previously reported $\mathrm{R} 506 \mathrm{H}$ mutation in DLD-1 cells, we found a novel POLD1 mutation in LoVo cells. LoVo was not included in the panel of human colorectal cancer cell lines in the above mentioned report. ${ }^{32}$ On the other hand, mutations in the POLE gene have never been reported in human individuals, although Matakidou et al pointed out the correlation between a POLE single-nucleotide polymorphism and poor patient outcomes in lung cancer. ${ }^{54}$ In this context, our present study is the first to report POLE mutation in human cells, and, therefore, F367S is the first identified POLE mutation in human diseases.

One important finding of this study is that all the three proofreading-mutant tumours are MMR deficient. DLD-1 and LoVo cells have been known as MMR-defective cell lines. ${ }^{36,37,55}$ In the genomic DNA extracted from the IC678 tumour, an unequivocal MSI phenomenon was observed and a deleterious MLH1 mutation was indeed found. As discussed above, the abrogation of either polymerase proofreading or MMR inevitably leads to an immense increase of mutations derived from the replication errors left on the genome. In this sense, concurrent defects of both systems are of particular interest, and one important problem is the causal relationship between the two molecular abnormalities. In general, the mutation spectra observed in cells defective in an anti-mutagenic system are known to be distinct depending on the system abrogated. It is now widely accepted that transitions, in particular G:C to A:T, are predominant in cells defective in MMR. ${ }^{16,56,57}$ On the other hand, A:T to C:G transversions predominate in proofreading-mutant mouse cells. ${ }^{31}$ In E. coli dnaQ mutators, all types of base substitutions, in addition to frameshifts, are known to increase dramatically. Among these base substitutions, A:T to G:C transitions are relatively frequent. ${ }^{58}$ The two POLD1 mutations in DLD-1 and LoVo cells were G:C to A:T transitions, and the POLE mutation found in the IC678 tumour was also transition (Table 2). On the other hand, MSH6 mutations in DLD-1 cells are a 1-bp deletion, that is, frameshift mutation, and a large sequence deletion/insertion. Although the former is indeed frequent in MMR-defective cells, the latter is exceptional. The large deletion involving from exons 3-8 of $\mathrm{MSH} 2$ in LoVo cells is also not explicable from MMR deficiency. Considering these facts, it may be more likely that the POLD1 and POLE mutations are the results of MMR deficiency than that defective polymerase proofreading has caused the mutations in the MMR genes. Furthermore, in this present study, we demonstrated that proofreading domain mutations were relatively infrequent in human colorectal cancer, whereas defective MMR is known to be frequently observed. ${ }^{59}$ This may also support the above hypothesis.

This problem can also be discussed from another point of view. The mutator phenotype derived from defects in the anti-mutagenic systems is believed to underlie tumourigenesis, causing the accumulation of mutations in various genes including oncogenes and tumour suppressor genes. ${ }^{60}$ APC, KRAS and TP53 are the representative genes, the alterations of which are regarded as playing crucial roles in the step-by-step tumourigenesis in the human colorectal epithelia. ${ }^{51-53}$ Intriguingly, DLD-1 cells, which are defective in both polymerase proofreading and MMR, harbour mutations in all these genes, and the mutations are all G:C to A:T transitions (Table 2). Also in LoVo cells with the POLD1 mutation, APC and KRAS are mutated, and the sequence alterations are G:C to A:T transitions (Table 2). Taking all these into account, it may be suggested that MMR deficiency contributes more than defective polymerase proofreading does to the mutator phenotype observed in human tumours.

The reason why proofreading domain mutations were infrequent in colorectal tumours is unknown. Needless to say, the possibility that mutations in small cell populations were not detected is not excluded. However, considering the facts that the mutations rates in the dnaQ mutators are two orders higher than those observed in MMR-defective E. coli mutators, ${ }^{4,5}$ such an extreme increase in the mutation rate may be toxic or, at least, disadvantageous for cells to survive. Indeed, the mutation rates are not widely different between DLD-1 cells, defective in both MMR and polymerase proofreading, and the other MMR-deficient human cell lines. ${ }^{14,16,17}$ In addition, the mutation rates observed in proofreading-defective mouse cells are at the same level as those in MMR gene-knockout mouse cells. ${ }^{31}$ Mutations occurring in the genomic sequences encoding the proofreading domains may be in fact selected according to their survival disadvantage, particularly in naturally occurring tumours. Indeed, the cell population harbouring the POLE F367S mutation is not predominant in the IC678 tumour (Figure 2c). Nevertheless, defective polymerase proofreading may contribute to the mutator phenotype as a 'booster' of MMR deficiency. In this context, the phenotypes of animals (or, possibly, cells) defective in both polymerase proofreading and MMR are of particular interest.

\section{CONFLICT OF INTEREST}

The authors declare no conflict of interest. 


\section{ACKNOWLEDGEMENTS}

We are most grateful to P Karran, H Maki and M Sekiguchi for their helpful advice. The expert assistance in DNA sequencing by Y Baba, K Funatsu, $\mathrm{Y}$ Ikematsu and K Miyamoto is also gratefully acknowledged. This study was supported by a Grant-in-aid for Cancer Research from the Ministry of Health, Labour and Welfare, and grants from the Ministry of Education, Science, Sports and Culture of Japan.

1. Drake JW: Comparative rates of spontaneous mutation. Nature 1969; 221: 1132.

2 Loeb LA, Kunkel TA: Fidelity of DNA synthesis. Annu Rev Biochem 1982; 51: 429-457.

3 Echols H: Mutation rate: some biological and biochemical considerations. Biochimie 1982; 64: 571-575.

4 Scheuermann R, Tam S, Burgers PM, Lu C, Echols H: Identification of the epsilonsubunit of Escherichia coli DNA polymerase III holoenzyme as the dnaQ gene product: a fidelity subunit for DNA replication. Proc Natl Acad Sci USA 1983; 80: 7085-7089.

5 Maki H, Horiuchi T, Sekiguchi M: Isolation of conditional lethal mutator mutants of Escherichia coli by localized mutagenesis. J Bacteriol 1983; 153: 1361-1367.

6 Modrich P: Mechanisms and biological effects of mismatch repair. Annu Rev Genet 1991; 25: 229-253.

7 Cox EC: Bacterial mutator genes and the control of spontaneous mutation. Annu Rev Genet 1976; 10: 135-156.

8 Fishel R, Lescoe MK, Rao MR et al: The human mutator gene homolog MSH2 and its association with hereditary nonpolyposis colon cancer. Cell 1993; 75: 1027-1038.

9 Leach FS, Nicolaides NC, Papadopoulos N et al: Mutations of a mutS homolog in hereditary nonpolyposis colorectal cancer. Cell 1993; 75: 1215-1225.

10 Loeb LA: A mutator phenotype in cancer. Cancer Res 2001; 61: 3230-3239.

11 de Wind N, Dekker M, Berns A, Radman M, te Riele H: Inactivation of the mouse Msh2 gene results in mismatch repair deficiency, methylation tolerance, hyperrecombination, and predisposition to cancer. Cell 1995; 82: 321-330.

12 Edelmann W, Yang K, Umar A et al: Mutation in the mismatch repair gene Msh6 causes cancer susceptibility. Cell 1997; 91: 467-477.

13 Reitmair AH, Risley R, Bristow RG et al: Mutator phenotype in Msh2-deficient murine embryonic fibroblasts. Cancer Res 1997; 57: 3765-3771.

14 Branch P, Hampson R, Karran P: DNA mismatch binding defects, DNA damage tolerance, and mutator phenotypes in human colorectal carcinoma cell lines. Cancer Res 1995; 55: 2304-2309.

15 Malkhosyan S, McCarty A, Sawai H, Perucho M: Differences in the spectrum of spontaneous mutations in the hprt gene between tumor cells of the microsatellite mutator phenotype. Mutat Res 1996; 316: 249-259.

16 Ohzeki S, Tachibana A, Tatsumi K, Kato T: Spectra of spontaneous mutations at the hprt locus in colorectal carcinoma cell lines defective in mismatch repair. Carcinogenesis 1997; 18: 1127-1133.

17 Bhattacharyya NP, Skandalis A, Ganesh A, Groden J, Meuth M: Mutator phenotypes in human colorectal carcinoma cell lines. Proc Natl Acad Sci USA 1994; 91 6319-6323.

18 Waga S, Bauer G, Stillman B: Reconstitution of complete SV4O DNA replication with purified replication factors. J Biol Chem 1994; 269: 10923-10934.

19 Sugino A: Yeast DNA polymerases and their role at the replication fork. Trends Biochem Sci 1995; 20: 319-323.

20 Kesti T, Flick K, Keranen S, Syvaoja JE, Wittenberg C: DNA polymerase epsilon catalytic domains are dispensable for DNA replication, DNA repair, and cell viability. Mol Cell 1999; 3: 679-685.

21 Yang CL, Chang LS, Zhang P et al: Molecular cloning of the cDNA for the catalytic subunit of human DNA polymerase delta. Nucleic Acids Res 1992; 20: 735-745.

22 Chung DW, Zhang JA, Tan CK, Davie EW, So AG, Downey KM: Primary structure of the catalytic subunit of human DNA polymerase delta and chromosomal location of the gene. Proc Natl Acad Sci USA 1991; 88: 11197-11201.

23 Chang LS, Zhao L, Zhu L, Chen ML, Lee MY: Structure of the gene for the catalytic subunit of human DNA polymerase delta (POLD1). Genomics 1995; 28: 411-419.

24 Kesti T, Frantti H, Syvaoja JE: Molecular cloning of the cDNA for the catalytic subunit of human DNA polymerase epsilon. J Biol Chem 1993; 268: 10238-10245.

25 Huang D, Pospiech H, Kesti T, Syvaoja JE: Structural organization and splice variants of the POLE1 gene encoding the catalytic subunit of human DNA polymerase epsilon. Biochem J 1999; 339 (Part 3): 657-665.

26 Simon M, Giot L, Faye G: The $3^{\prime}$ to $5^{\prime}$ exonuclease activity located in the DNA polymerase delta subunit of Saccharomyces cerevisiae is required for accurate replication. Embo J 1991; 10: 2165-2170.

27 Morrison A, Sugino A: The $3^{\prime}->5^{\prime}$ exonucleases of both DNA polymerases delta and epsilon participate in correcting errors of DNA replication in Saccharomyces cerevisiae. Mol Gen Genet 1994; 242: 289-296.

28 Morrison A, Johnson AL, Johnston LH, Sugino A: Pathway correcting DNA replication errors in Saccharomyces cerevisiae. Embo J 1993; 12: 1467-1473.

29 Goldsby RE, Lawrence NA, Hays LE et al: Defective DNA polymerase-delta proofreading causes cancer susceptibility in mice. Nat Med 2001; 7: 638-639.
30 Goldsby RE, Hays LE, Chen $X$ et al: High incidence of epithelial cancers in mice deficient for DNA polymerase delta proofreading. Proc Natl Acad Sci USA 2002; 99 : 15560-15565.

31 Albertson TM, Ogawa M, Bugni JM et al: DNA polymerase epsilon and delta proofreading suppress discrete mutator and cancer phenotypes in mice. Proc Natl Acad Sci USA 2009; 106: 17101-17104.

32 Flohr T, Dai JC, Buttner J, Popanda O, Hagmuller E, Thielmann HW: Detection of mutations in the DNA polymerase delta gene of human sporadic colorectal cancers and colon cancer cell lines. Int J Cancer 1999; 80: 919-929.

33 Kolodner RD, Hall NR, Lipford J et al: Structure of the human MLH1 locus and analysis of a large hereditary nonpolyposis colorectal carcinoma kindred for mlh1 mutations. Cancer Res 1995; 55: 242-248.

34 Zhao $\mathrm{Y}$, Miyashita $\mathrm{K}$, Ando $\mathrm{T}$ et al: Exclusive KRAS mutation in microsatellite-unstable human colorectal carcinomas with sequence alterations in the DNA mismatch repair gene, MLH1. Gene 2008; 423: 188-193.

35 Oda S, Oki E, Maehara Y, Sugimachi K: Precise assessment of microsatellite instability using high resolution fluorescent microsatellite analysis. Nucleic Acids Res 1997; 25: 3415-3420.

36 Papadopoulos N, Nicolaides NC, Liu B et al: Mutations of GTBP in genetically unstable cells. Science 1995; 268: 1915-1917.

37 Boyer JC, Umar A, Risinger JI et al: Microsatellite instability, mismatch repair deficiency, and genetic defects in human cancer cell lines. Cancer Res 1995; 55: 6063-6070.

38 Shirasawa S, Furuse M, Yokoyama N, Sasazuki T: Altered growth of human colon cancer cell lines disrupted at activated Ki-ras. Science 1993; 260: 85-88.

$39 \mathrm{Jia}$ LQ, Osada M, Ishioka C et al: Screening the p53 status of human cell lines using a yeast functional assay. Mol Carcinog 1997; 19: 243-253.

40 Gayet J, Zhou XP, Duval A et al: Extensive characterization of genetic alterations in a series of human colorectal cancer cell lines. Oncogene 2001; 20: 5025-5032.

41 Hamada K, Monnai M, Kawai K et al: Liver metastasis models of colon cancer for evaluation of drug efficacy using NOD/Shi-scid IL2Rgammanull (NOG) mice. Int J Oncol 2008; 32: 153-159.

42 Ikediobi ON, Davies H, Bignell G et al: Mutation analysis of 24 known cancer genes in the NCl-60 cell line set. Mol Cancer Ther 2006; 5: 2606-2612.

43 Rowan AJ, Lamlum H, Ilyas M et al: APC mutations in sporadic colorectal tumors: a mutational 'hotspot' and interdependence of the 'two hits'. Proc Natl Acad Sci USA 2000; 97: 3352-3357.

44 da Costa LT, Liu B, el-Deiry W et al: Polymerase delta variants in RER colorectal tumours. Nat Genet 1995; 9: 10-11.

45 Cullmann G, Hindges R, Berchtold MW, Hubscher U: Cloning of a mouse cDNA encoding DNA polymerase delta: refinement of the homology boxes. Gene 1993; 134: 191-200.

46 Fazlieva R, Spittle CS, Morrissey D, Hayashi H, Yan H, Matsumoto Y: Proofreading exonuclease activity of human DNA polymerase delta and its effects on lesion-bypass DNA synthesis. Nucleic Acids Res 2009; 37: 2854-2866.

47 Huang D, Knuuti R, Palosaari H, Pospiech H, Syvaoja JE: cDNA and structural organization of the gene Pole1 for the mouse DNA polymerase epsilon catalytic subunit. Biochim Biophys Acta 1999; 1445: 363-371.

48 Oki E, Oda S, Maehara Y, Sugimachi K: Mutated gene-specific phenotypes of dinucleotide repeat instability in human colorectal carcinoma cell lines deficient in DNA mismatch repair. Oncogene 1999; 18: 2143-2147.

49 Oda S, Maehara Y, Ikeda Y et al: Two modes of microsatellite instability in human cancer: differential connection of defective DNA mismatch repair to dinucleotide repeat instability. Nucleic Acids Res 2005; 33: 1628-1636.

50 Papadopoulos N, Nicolaides NC, Wei YF et al: Mutation of a mutL homolog in hereditary colon cancer. Science 1994; 263: 1625-1629.

51 Fearon ER, Vogelstein B: A genetic model for colorectal tumorigenesis. Cell 1990; 61: 759-767.

52 Wood LD, Parsons DW, Jones S et al: The genomic landscapes of human breast and colorectal cancers. Science 2007; 318: 1108-1113.

53 Sjoblom T, Jones S, Wood LD et al: The consensus coding sequences of human breast and colorectal cancers. Science 2006; 314: 268-274.

54 Matakidou A, el Galta R, Webb EL et al: Genetic variation in the DNA repair genes is predictive of outcome in lung cancer. Hum Mol Genet 2007; 16: 2333-2340.

55 Liu B, Nicolaides NC, Markowitz S et al: Mismatch repair gene defects in sporadic colorectal cancers with microsatellite instability. Nat Genet 1995; 9: 48-55.

56 Schaaper RM, Dunn RL: Spectra of spontaneous mutations in Escherichia coli strains defective in mismatch correction: the nature of in vivo DNA replication errors. Proc Natl Acad Sci USA 1987; 84: 6220-6224.

57 Andrew SE, Reitmair AH, Fox J et al: Base transitions dominate the mutational spectrum of a transgenic reporter gene in MSH2 deficient mice. Oncogene 1997; 15: $123-129$.

58 Isbell RJ, Fowler RG: Temperature-dependent mutational specificity of an Escherichia coli mutator, dnaQ49, defective in $3^{\prime}-5^{\prime}$ exonuclease (proofreading) activity. Mutat Res 1989; 213: 149-156.

59 Arzimanoglou II, Gilbert F, Barber HR: Microsatellite instability in human solid tumors. Cancer 1998; 82: 1808-1820.

60 Loeb LA, Loeb KR, Anderson JP: Multiple mutations and cancer. Proc Natl Acad Sci USA 2003; 100: 776-781. 